\title{
Clinical vitamin-A deficiency and associated factors among pregnant and lactating women in Northwest Ethiopia: a community-based cross-sectional study
}

\author{
Abebaw Baytekus ${ }^{1}$, Amare Tariku² and Ayal Debie ${ }^{3^{*}}$
}

\begin{abstract}
Background: Vitamin A deficiency is known for its adverse health consequences, such as blindness, growth retardation and death. To curb the problem, Ethiopia has implemented various public health measures although little has been done to examine the deficiency among pregnant and lactating women. As a result, this study assessed the prevalence of Vitamin A deficiency and associated factors among pregnant and lactating women in Lay Armachiho district, northwest Ethiopia.

Methods: A community-based cross-sectional study was conducted on pregnant and lactating women in Lay Arimachiho district, northwest Ethiopia, using the multistage systematic sampling technique to select participants. The binary logistic regression model was fitted to test the effect of exposure variables, and the Adjusted Odds Ratio (AOR) with a 95\% Confidence Interval $(\mathrm{Cl})$ and $p$-value $<0.05$ were computed to identify the significance and the strength of the associations of variables with Vitamin A deficiency.

Results: The study revealed that $13.7 \%$ of the pregnant and lactating women had night blindness and $0.4 \%$ had also Bitot's Spot. Over 35 years of age of mothers (AOR $=2.74 ; 95 \% \mathrm{Cl}: 1.15,7.43$ ), less than USD 22.7 household monthly income (AOR $=8.9 ; 95 \% \mathrm{Cl}: 4.54,21.73)$, and poor hand washing practices after toilets $(\mathrm{AOR}=8.87 ; 95 \% \mathrm{Cl}$ : $4.43,18.68)$ were positively associated with $V A D$, while mothers' access to the media ( $A O R=0.20 ; 95 \% \mathrm{Cl}: 0.07,0.59$ ), formal education ( $A O R=0.09 ; 95 \% \mathrm{Cl}: 0.03,0.41$ ), over 18 years of age at first marriage ( $\mathrm{AOR}=0.19 ; 95 \% \mathrm{Cl}: 0.08,0.36$ ), and no fasting ( $\mathrm{AOR}=0.14 ; 95 \% \mathrm{Cl}: 0.04,0.46)$ were negatively associated.

Conclusions: Maternal Vitamin A deficiency was the major public health problem in Lay Armachiho district. Over 35 years of age of mothers, less than USD 22.7 household monthly income and poor hand washing practices after toilets were high risks for VAD, while mothers' access to the media, formal education, over 18 years at first marriage, and no fasting were low risks. Therefore, community awareness about the risk of early marriage, poor hand hygiene practices after toilets, and fasting during pregnancy and lactating period were essential. Organizations working on maternal health need to focus on mothers with low incomes in order to reduce their deficiency in Vitamin A.
\end{abstract}

Keywords: Night blindness, Bitot's spot, Pregnancy, Lactating, Vitamin A deficiency, Ethiopia

\footnotetext{
* Correspondence: debieayal@gmail.com

${ }^{3}$ Department of Health Systems and Policy, Institute of Public Health,College

of Medicine and Health Sciences, University of Gondar, Gondar, Ethiopia

Full list of author information is available at the end of the article
}

(c) The Author(s). 2019 Open Access This article is distributed under the terms of the Creative Commons Attribution 4.0 International License (http://creativecommons.org/licenses/by/4.0/), which permits unrestricted use, distribution, and reproduction in any medium, provided you give appropriate credit to the original author(s) and the source, provide a link to the Creative Commons license, and indicate if changes were made. The Creative Commons Public Domain Dedication waiver (http://creativecommons.org/publicdomain/zero/1.0/) applies to the data made available in this article, unless otherwise stated. 


\section{Background}

Vitamin A Deficiency (VAD) is a major public health problem worldwide and a known cause of blindness, growth retardation and death, specially in developing countries [1]. It may also cause infertility,miscarriage, dry skin and hair as well as gastroenteritis, throat and chest infections [2-4]. The problem is common among children, pregnant and lactating mothers whose the requirement for vitamin-A is high because they need to compensate for their execessive physiological demand [5].

The cut-offs to declare the public health importance of clinical VAD are set to ease policy decisions. Accordingly, maternal VAD is considered as a public health problem if $\geq 5 \%$ or $0.5 \%$ of the mothers are affected with night blindness $(\mathrm{XN})$ or Bitot's Spot (X1B), respectively. According to this criteria, Vitamin-A deficiency is a worldwide public health problem. Hence, $7.8 \%$ of pregnant women are vitamin-A deficienct [6]. Furthermore, 9.8 million women worldwide are at risk for VAD. The highest burden of prenatal VAD was noted in African (9.8\%) and South-East Asian (9.9\%) [6, 7]. Low socio-economic status and impaired health conditions and dietary intake are commonly reported attributes of maternal VAD [8-14].

A few local studies reported that VAD had severe public health importance in both children and mothers [8, 9, 15-17]. The limited literature showed that 17.3 and $37.9 \%$ of pregnant mothers in north and south Ethiopia had night blindness and sub-clinical VAD (serum retinol $<0.7 \mu \mathrm{mol} / \mathrm{L}$ ) $[8,9]$. Considering the severity of the problem, high dose $(200,000 \mathrm{IU})$ of vitamin-A has been universally provided for all lactating mothers. Yet, the micronutrient supplementation strategy did not target non-pregnant and non-lactating mothers to optimize the preconception maternal vitamin-A reserve [18]. Inspite of the fact that maternal breast milk vitamin-A concentration directly determines vitamin-A intake of breastfed children [9, 19-21], less research attention has been given to investigate the burden and the factors associated with maternal VAD among lactating women. Therefore, this study aimed to assess the prevalence of clinical VAD and associated factors among pregnant and lactating mothers in Lay Armachiho district, northwest Ethiopia.

\section{Methods}

\section{Study settings and design}

This community based cross-sectional study was conducted in Lay Armachiho district from February to March 2017. The district is situated in North Gondar administrative zone, the Amhara National Regional State, $210 \mathrm{~km}$ from Bahir Dar, capital of the region. According to the 2016/17 Central Stastical Agency estimation, the total population of the district was 140,417; pregnant and lactating mothers accounted for 3.36 and $3.09 \%$ of the population, respectively. Cereals, grains, roots and tubers are the commonest food products of the district.

\section{Population and sampling procedure}

All pregnant and lactating women who lived in Lay Armachiho district were the source population, while all pregnant and lactating mothers in slected kebeles of the district were the study population. Lactating woman was defined as a breastfeeding mother who had less than one year old children.

The sample size was determined using the single population proportion formula considering a 95\% level of confidence, $4 \%$ margin of error and a prevalence of maternal night blindness in Tahitay Koraro district, Tigray Region of $17.3 \%$ [9]. A 10\% adjustment for non-response rate and 2 design effect yielded a sample of 754. Sample size for the second objective (determinants of VAD) was also calculated by assuming a $22 \%$ proportion of night blindness among pregnant and lactating mothers aged over 35 years, and less than ETB 500 household monthly income (24\%) [9], $80 \%$ power, $95 \%$ level of confidence, $10 \%$ nonresponse rate and 2 design effect yielded 317 and 517, lower than the sample (754) for the first objective. Thus, 754 was taken as the final sample.

The multi-stage systematic sampling technique was used to select eligible participants; 6 of the 31 kebeles (lowest administration units) were selected by the lottery method. Then, 392 and 362 pregnant and lactating women were proportionally allocated to the selected kebeles. Finaly, the systematic sampling technique was employed to select eligible participants, and pregnancy was confirmed by mothers' own reports.

\section{Measurments}

Vitamin A deficiency was clinically confirmed by night blindness and Bitot's Spot, while history of night blindness (dafint) was elicited by asking mothers in their local language for a word that stood for night blindness. Information on whether a woman faced any difficulty in identifying objects in dim light, especially at sun set, was collected [22]. On the other hand, mothers with opaque whitish/cheezy appearance deposits on sclera of their eye/s were deemed as having Bitot's Spot [22, 23]. Consequently, if participants had at least one of the clinical signs (night blindness or Bitot's Spot), the woman was defined as Vitamin-A deficient.

A standardized tool was used to measure the dietary diversity of the participants. The tool comprised 14 food groups, and food items consumed by participants in the previous 24-h were labeled as "food groups". The final figures participants scored of the maximum of 14 based on their consumption of diversified food were categorized as "low", "medium" and "high" if they reported to have consumed $\leq 3,4-5$ and $\geq 6$ food groups, respectively [24]. Furthermore, a seven-day quasi-food frequency questionnaire was used to estimate mothers' dietary intake for vitamin-A rich food. Participants were requested 
to report the number of days they ate the listed vitaminA rich food groups one week before the data collection. In this study, pregnant or lactating mothers were also considered as fasting when they didn't consume any thing for a minimum of nine hours (morning to 3:00 PM) except weekends, and couldn't take any animal products at any time (day and night) for at least one month before the actual data collection.

\section{Data collection tools and procedures}

A structured interviewer administered questionnaire was developed by reviewing literatures $[8,9,24]$, and the questionnaire was first developed in English and translated into Amharic and back to English to maintain consistency. Six deploma level and two BSc degree graduate nurses were recruited to collect data and supervise the process, respectively. A two-day training was given to both groups on how to identify the clinical features of VAD (night blindness and/or Bitot's Spot), interview techniques and data collection procedures. The questionnaire was modified based on the pre-test administered at Musie Bamb kebele on 38 mothers.

\section{Data management and analysis}

Data were entered and analysed using Epi Info version 7 and SPSS version 20, respectively after cleaning to check accuracy, consistency and the identification of missed values. Descriptive statistics, such as frequency distributions, percentages, means, and standard deviations were used to summarize variables. A binary logistic regression model was fitted to test the effect of exposure variables on VAD. First, bivariable analysis was carried out to examine the effect of each independent variable on the outcome variable. Variables with $p$-values of $<0.2$ in the bivariable analysis were fitted into the multivariable analysis. In the final model, independent variables with $p$-values of $<0.05$ were considered as having statistically significant association with VAD. The strength of associations was determined using the adjusted odds ratio with $95 \% \mathrm{CI}$.

\section{Results}

Socio-economic and dietary habit related characteristics

A total of 742 pregnant and lactating women participated in the study with a response rate of $98.4 \%$. The mean age of respondents was $30.4 \pm(6.5 \mathrm{SD})$ years, while the mean age at first marriage was $16.5 \pm(3.6 \mathrm{SD})$ years. Nearly all $(98.8 \%)$ of the respondents were married. Subsistence farming $(92.65 \%)$ was the major source of livelihood for the women in the study area (Table 1 ).

\section{Nutrition and obstetric related chacterstics}

Nearly one-third (32.9\%) of the respondents had two or more under-five children, and $88.0 \%$ had antenatal care follow-ups. The majority (81.2\%) of the respondents were well-nourished (MUAC $>23 \mathrm{~cm}$ ). More than onethird (41.0\%) had low dietary diversity scores (Table 2 ). About 22 and $19.1 \%$ of the mothers consumed milk and green leafy vegetables three or more times per week, respectively (Fig. 1).

\section{Knowledge of vitamin-a related issues}

About $40 \%$ (41\%) of the women had no information about VAD; over half (52.3\%) did not know the signs and symptoms of VAD. More than two-thrids (71.8\%) believed that VAD could not be prevented with diet (Table 3).

\section{Vitamin-A deficiency}

Out of 742 the pregnant and lactating women, 13.7\% had night blindness and $0.4 \%$ had also Bitot's Spot. Of these, 6.6 and $7.1 \%$ were lactating and pregnant mothers, respectively.

\section{Factors associated with VAD}

In the multivariable analysis, the odds of VAD among pregnant and lactating women who had formal education were $91 \%$ less likely $(\mathrm{AOR}=0.09 ; 95 \% \mathrm{CI}: 0.03$, 0.41) compared to women who had no formal education. The finding indicated that the proportion of VAD among women who had no formal education was $20.6 \%$, that is, $19 \%$ higher compared with those who had formal education. Moreover, lesser odds of VAD were noted among women who had access to the media $(\mathrm{AOR}=$ 0.20 ; CI: $0.07,0.59$ ) by $80 \%$. Accordingly, only $3.72 \%$ of the participants had VAD among women with exposure to radio/TV, 13\% lower compared with women with no access to the media. Women who had no fasting habits $(\mathrm{AOR}=0.14 ; \mathrm{CI}: 0.04,0.46)$ were also $86 \%$ less likely to have VAD. Similarly, the magnitude of VAD among fasting women was $16.43 \%$ and only $4.71 \%$ among nonfasting mothers. Women whose age at first marriage was above 18 years $(\mathrm{AOR}=0.19$; CI: $0.08,0.36)$ had lesser VAD compared with their counterparts. The study showed that 4.46 and $19.03 \%$ of pregnant and lactating women had VAD among participants whose age at first marriage was above and below 18 years, respectively. In contrast, higher odds of VAD were noted among women whose households' monthly income was less than US\$ $22.7(\mathrm{AOR}=8.9 ; 95 \% \mathrm{CI}: 4.54,21.73)$ compared with their counterparts. The study indicated that the prevalence of VAD among respondents who had less than US\$ 22.7 monthly household income were 33.33 and $9.51 \%$ more affected than those whose monthly income was more than US\$ 45.5. Participants who had no hand washing practices after toilets (AOR $=8.87$; 95\% CI: 4.43,18.68) were 8.87 times more likely to face VAD compared with women who washed hands after toilets. Women over 35 years of age $(\mathrm{AOR}=2.74 ; \mathrm{CI}: 1.15,7.43)$ were 2.74 times more likely to have VAD compared with those 25-35 
Table 1 Socio-demographic and economic characteristics of pregnant and lactating women, Lay- Armachiho district, northwest Ethiopia, 2017

\begin{tabular}{|c|c|c|c|}
\hline Variables & Category & Frequency & Percent $(\%$ \\
\hline \multirow[t]{2}{*}{ Maternal status } & Pregnant & 381 & 51.3 \\
\hline & Lactating & 361 & 48.7 \\
\hline \multirow[t]{2}{*}{ Maternal education } & No formal education & 477 & 64.3 \\
\hline & Formal education & 265 & 35.7 \\
\hline \multirow[t]{2}{*}{ Husband education } & No formal education & 393 & 53.0 \\
\hline & Formal education & 349 & 47.0 \\
\hline \multirow[t]{2}{*}{ Maternal occupation } & House wife & 703 & 94.7 \\
\hline & Government employee & 39 & 5.3 \\
\hline \multirow[t]{2}{*}{ Husband occupation } & Farmer & 687 & 92.6 \\
\hline & Government employee & 55 & 7.4 \\
\hline \multirow[t]{3}{*}{ Distance to source of water (minutes) } & $<15$ & 216 & 29.1 \\
\hline & $15-30$ & 298 & 40.2 \\
\hline & $>30$ & 228 & 30.7 \\
\hline \multirow[t]{2}{*}{ Diarrhea in the last 2 wks } & Yes & 711 & 95.8 \\
\hline & No & 31 & 4.2 \\
\hline \multirow[t]{3}{*}{ Wash hands with soap/ash after toilet } & Not & 147 & 70.6 \\
\hline & Sometimes & 524 & 19.8 \\
\hline & Always & 71 & 9.6 \\
\hline \multirow[t]{3}{*}{ Age of mothers in years } & $<25$ & 136 & 18.3 \\
\hline & $25-35$ & 377 & 50.8 \\
\hline & $>35$ & 229 & 30.9 \\
\hline \multirow[t]{3}{*}{ Household monthly income (USD) } & $<22.7$ & 129 & 17.4 \\
\hline & $22.7-45.5-$ & 245 & 33.0 \\
\hline & $>45.5$ & 368 & 49.6 \\
\hline \multirow[t]{2}{*}{ Age at first marriage in years } & $<18$ & 473 & 63.7 \\
\hline & $>18$ & 269 & 36.3 \\
\hline \multirow[t]{2}{*}{ Treatment of water } & Yes & 552 & 74.4 \\
\hline & No & 190 & 25.6 \\
\hline
\end{tabular}

years of age. This finding showed thatabout $20.09 \%$ of the women over 35 years and $9.56 \%$ of mothers below 25 years had VAD. Furthermore, this study indicated that $16.45 \%$ of women who had low dietary diversity faced VAD (Table 4).

\section{Discussion}

This study aimed to asses the prevalence of VAD and associated factors among pregnant and lactating mothers in Lay Armachiho district, northwest Ethiopia. The findings showed that $13.7 \%$ (95\% CI, 11.3,16.3) of the pregnant and lactating women had night blindness and $0.4 \%$ had Bitot's Spot. The reported burden of night blindness and Bitot's Spot confirmed the public health importance of VAD. One of the main reasons for high VAD might be the low Vitamin A supplementation during pregnancy and postpartum period.
In this study, Vitamin A supplementation among mothers was only $4.7 \%$.

The prevalence of night blindness was consistent with that of a study conducted in the Republic of Congo (16\%) [10] and Pakistan (16.2\%) [25]. Neverthless, the finding was lower than those of studies conducted at Neader Adet (18.6\%) [11], Tahitay Koraro (17.3\%) [9], Sidama zone (37.9\%) [8], Bangladish (37\%) [26], and Nepal (21\%) [27]. However, our result was higher than those of studies conducted in Atsede-Tsimbla (1.22\%) [16], Wukro (5.8\%) [15], Ethiopia (1.8\%) [12], East Med (7.8\%), West Pacific (5\%) [28], Cameroon (6\%), Ghana (7.7\%), Congo (8\%), Zambia (5.7\%), Uganda (8.3\%), and Tanzania $(2.7 \%)[7,29]$. In this study, the prevalence of Bitot's Spot $(0.4 \%)$ was lower than the results of studies conducted in the pastoral areas of Ethiopia (1.6\%), among grain farmers (1.1\%), national level (1\%) [12], and 
Table 2 Nutrition and obstetric related characteristics of pregnant and lactating women, Lay- Armachiho district, northwest Ethiopia, 2017

\begin{tabular}{llll}
\hline Characteristics $(N=742)$ & Category & Frequency & Percent(\%) \\
\hline Number of $<5$ children & $<2$ & 498 & 67.1 \\
Total number of births & $>2$ & 143 & 19.3 \\
Birth spacing & $>5$ & 412 & 55.5 \\
Mothers MUAC & $<3$ years & 165 & 34.9 \\
& $>3$ years & 460 & 22.2 \\
Fasting & $<23 \mathrm{~cm}$ & 140 & 62.0 \\
& $>23 \mathrm{~cm}$ & 602 & 18.9 \\
Families eat organ meat & Yes & 571 & 77.1 \\
& No & 171 & 23.0 \\
Meal frequency & No & 239 & 67.8 \\
& $>3$ meals & 570 & 32.2 \\
& 3 meals & 95 & 76.8 \\
Dietary diversity score & $<2$ meals & 77 & 12.8 \\
& Low & 304 & 10.4 \\
& Medium & 355 & 41.0 \\
& High & 83 & 47.8 \\
\hline
\end{tabular}

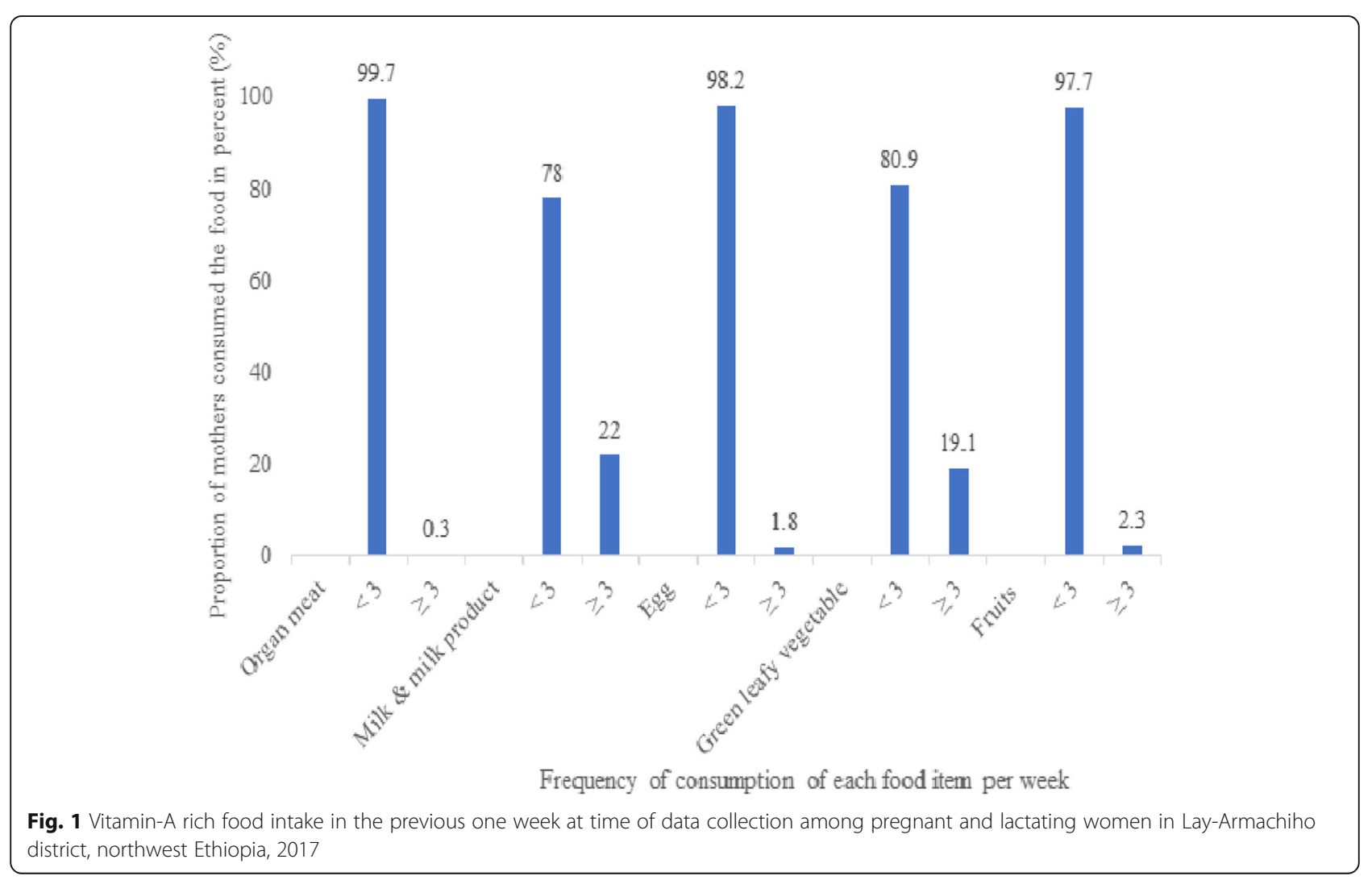

Frequency of consumption of each food item per week

Fig. 1 Vitamin-A rich food intake in the previous one week at time of data collection among pregnant and lactating women in Lay-Armachiho district, northwest Ethiopia, 2017
Congo (19\%) [10]. The finding was consistent with that of cash-crop growers $(0.4 \%)$ but higher than that of enset cultivating zones $(0.0 \%)$ [12]. The possible explanation for the variations might be differences in study settings. That means, some studies were conducted in urban communities among well informed participants. Differences in study periods might also affect the Vitamin A status of mothers.

In this study, pregnant and lactating women over 35 years of age were 2.74 times more likely to be vitamin A deficient compared to mothers aged 25-35 years. This finding was supported by those of studies conducted in Tahtay Koraro of Tigray region [9], Sidama zone, southern Ethiopia [8] and rural Terai of Nepal [30], perhaps because mothers aged over 35 years had more pregnancies and births which depleted their vitamin A storage.

Households with less than USD 17.6 monthly income were 8.9 times more likely to be vitamin A deficient than those whose household monthly income was USD $>35.1$. The result was similar to those of studies reported in Tahtay Koraro, Tigray region, and rural Cambodia $[9,13]$, perhaps because women who had relatively moderate income could get or consume more vitamin A rich foods than the poorest; the richest might also use maternal health services more than the poorest.

Women who had formal education and access to the media programs were 91 and $80 \%$ less likely to be vitamin A deficient compared to their counterparts, respectively. This finding was consistent with those of studies done in Sidama 
Table 3 Knowledge of pregnant and lactating women on Vitamin-A in Lay-Armachiho district, northwest Ethiopia, 2017

\begin{tabular}{|c|c|c|c|}
\hline Characteristics & Category & Frequency & Percent (\%) \\
\hline \multirow[t]{2}{*}{ Heard about VAD } & Yes & 438 & 59.0 \\
\hline & No & 304 & 41.0 \\
\hline \multirow[t]{5}{*}{ Mentioned sign of VAD } & Weakness & 36 & 4.9 \\
\hline & Becomes sick & 27 & 3.6 \\
\hline & night blindness & 176 & 23.7 \\
\hline & Total blindness & 115 & 15.5 \\
\hline & Don't know & 388 & 52.3 \\
\hline \multirow[t]{3}{*}{ Causes of VAD } & Poor intake of variety of food & 84 & 11.3 \\
\hline & Eating too little food & 61 & 8.2 \\
\hline & Don't know & 597 & 80.5 \\
\hline \multirow[t]{2}{*}{ Prevention of VAD with foods } & Yes & 209 & 28.2 \\
\hline & No & 533 & 71.8 \\
\hline \multirow[t]{4}{*}{ Prevention of VAD } & Vitamin A rich food & 96 & 12.9 \\
\hline & Vitamin A added food & 2 & 0.3 \\
\hline & Vitamin A supplementation & 35 & 4.7 \\
\hline & Don't know & 609 & 82.1 \\
\hline \multirow[t]{5}{*}{ Mentioned vitamin A rich food sources } & Green leafy vegetables & 79 & 10.6 \\
\hline & Fruits & 31 & 4.2 \\
\hline & Eggs & 13 & 1.8 \\
\hline & Organ meat & 4 & 0.5 \\
\hline & Milk and milk product & 24 & 3.2 \\
\hline
\end{tabular}

zone, southern Ethiopia [8], Bangladish [26], and rural south India [14]. The possible explanation might be that educated and mass media program accessing women had better information and knowledge about the sources of vitamin $\mathrm{A}$ rich foods and prevention strategies for vitamin A deficiency.

Women with no fasting were $86 \%$ less likely to be vitamin A deficient than those who were fasting, perhaps because women who fasted had poor vitamin A intake, negatively affecting their hepatic store. Poor dietry intake coupled with depleted liver storage of Vitamin-A predisposed mothers to VAD.

Women who always washed their hands after toilets with ash or soap were less likely to be vitamin A deficient by $92 \%$ than women who only sometimes did that. The finding was supported by those of studies in Bangladish [26] and Tahtay Koraro [9]. The possible explanation might be that women who had poor hand washing practices after toilets were highly prone to infections due to contaminations that subsequently led to disease-induced VAD. Furthermore, this study indicated that a high proportion of women who had low dietary diversity scores might have enhanced their exposure to vitamin A deficiency. This result was supported by a finding in South Africa [31]. This might be due to a low intake of vitamin A enrich foods as a result of low diversification of foods. The limitation of this study was the use of maternal self- report of amenorrhea, increasing uterine size to detect pregnancy for mothers who had no pregnancies test results. This might have reduced the reliability of pregnancies since the causes for amenorrhea might have been other conditions, for instance, menustrial/ endocrine disorders, malnutrition etc. Another limitation was the reliance on symptoms and signs of vitamin A without measuring the serum retinol level. Seasonal variations of maternal Vitamin A status were not addressed in this study. As it employed the cross-sectional study design, over work was bound to miss/ lack the comparative longitudinal characterstics. Besides, it was not able to describe other possible causes of the night blindness.

\section{Conclusion}

Overall, maternal VAD was a major public health problem in the study area. Over 35 years of age, age at first marriage $>18$ years, no fasting, poor hand washing practices after toilets, and less than USD 22.7 household monthly income were the factors associated with maternal VAD. Therefore, strengthening the awareness of pregnant and lactating women about the risk of early marriage, encouraging hand washing practices after toilets, and no fasting during pregnancy and lactating periods are recommended. Mothers had better access to the media, particularly health related programs. Women should also take a more 
Table 4 Factors associated with VAD among pregnant and lactating women in Lay- Armachiho district, northwest Ethiopia, 2017

\begin{tabular}{|c|c|c|c|c|c|c|}
\hline \multirow[t]{2}{*}{ Variables } & \multirow[t]{2}{*}{ Category } & \multicolumn{2}{|l|}{ VAD } & \multirow{2}{*}{$\begin{array}{l}\text { Proportion } \\
\text { of VAD (\%) }\end{array}$} & \multirow[t]{2}{*}{ COR $(95 \% \mathrm{Cl})$} & \multirow[t]{2}{*}{$\mathrm{AOR}(95 \% \mathrm{Cl})$} \\
\hline & & Yes & No & & & \\
\hline \multirow[t]{2}{*}{ Maternal education } & No formal & 98 & 379 & 20.55 & 1 & 1 \\
\hline & Formal & 4 & 261 & 1.51 & $0.06(0.02,0.16)$ & $0.09(0.03,0.41)^{*}$ \\
\hline \multirow[t]{2}{*}{ Listen radio/TV } & Yes & 7 & 181 & 3.72 & $0.58(0.10,0.45)$ & $0.20(0.07,0.59)^{*}$ \\
\hline & No & 95 & 459 & 17.15 & 1 & 1 \\
\hline \multirow[t]{2}{*}{ Diarrhea in last 2 wks } & Yes & 9 & 22 & 29.03 & $2.72(1.22,6.80)$ & $1.75(0.37,4.51)$ \\
\hline & No & 93 & 618 & 13.08 & 1 & 1 \\
\hline \multirow[t]{3}{*}{ Household monthly income (USD) } & $<22.7$ & 43 & 86 & 33.33 & $4.76(2.87,7.89)$ & $8.90(4.54,21.73)^{*}$ \\
\hline & $22.7-45.5$ & 24 & 221 & 9.80 & $1.03(0.59,1.79)$ & $1.71(0.79,4.54)$ \\
\hline & $>45.5$ & 35 & 333 & 9.51 & 1 & 1 \\
\hline \multirow[t]{2}{*}{ Age at first marriage in years } & $<18$ & 90 & 383 & 19.03 & 1 & 1 \\
\hline & $>18$ & 12 & 257 & 4.46 & $0.20(0.11,0.37)$ & $0.19(0.08,0.36)^{*}$ \\
\hline \multirow[t]{3}{*}{ Age of women in years } & $25-35$ & 43 & 334 & 11.41 & 1 & 1 \\
\hline & $<25$ & 13 & 123 & 9.56 & $0.82(0.45,1.43)$ & $0.87(0.43,2.62)$ \\
\hline & $>35$ & 46 & 183 & 20.09 & $1.95(1.26,3.22)$ & $2.74(1.15,7.43)^{*}$ \\
\hline \multirow[t]{3}{*}{ Dietary diversity score } & Low & 50 & 254 & 16.45 & 1 & 1 \\
\hline & Medium & 44 & 311 & 12.39 & $0.72(0.46,1.11)$ & $0.93(0.71,1.34)$ \\
\hline & High & 8 & 75 & 9.64 & $0.54(0.25,1.19)$ & $0.67(0.43,1.51)$ \\
\hline \multirow[t]{3}{*}{ Wash hands with soap/ash after toilet } & Sometimes & 48 & 476 & 9.16 & 1 & 1 \\
\hline & No hand wash & 52 & 95 & 35.37 & $5.43(3.46,8.51)$ & $8.87(4.43,18.68)^{*}$ \\
\hline & Always & 2 & 69 & 2.82 & $0.29(0.07,1.21)$ & $0.08(0.02,0.76)^{*}$ \\
\hline \multirow[t]{2}{*}{ Number of births } & $<5$ & 50 & 362 & 12.14 & 1 & 1 \\
\hline & $>5$ & 52 & 278 & 15.76 & $1.35(1.07,2.53)$ & $1.21(0.52,3.31)$ \\
\hline \multirow[t]{2}{*}{ No of $<5$ children } & $<2$ & 62 & 436 & 12.45 & 1 & 1 \\
\hline & $>2$ & 40 & 204 & 16.39 & $1.38(0.99,2.69)$ & $1.13(0.48,5.12)$ \\
\hline \multirow[t]{2}{*}{ Fasting } & Yes & 94 & 478 & 16.43 & 1 & 1 \\
\hline & No & 8 & 162 & 4.71 & $0.25(0.12,0.52)$ & $0.14(0.04,0.46)^{*}$ \\
\hline
\end{tabular}

*Significant at p-value <0.05; AOR: Adjusted Odds Ratio; COR: Crude Odds Ratio

diversified food to get more Vitamin A since vitamin A supplementation noted in this study was very low, healthcare providers need to improve vitamin A supplementation to maintain women's Vitamin A stasus because pregnancy and lactating periods require more vitamin A. Furthermore, researchers have to focus on measuring retinol concentration and assess seasonal variations of maternal VAD using comparative longitudinal designs in order to examine the Vitamin A status of exposed and unexposed groups of mothers. Organizations working on maternal health need to focus on low income mothers to reduce their VAD related problems.

\section{Supplementary information}

Supplementary information accompanies this paper at https://doi.org/10. 1186/s12884-019-2663-2.

Additional file 1. : English version questionnaire.

\section{Abbreviations}

ARI: Acute Respiratory Infection; MMR: Maternal Mortality Ratio; SPSS: Statistical Package for Social Sciences; UNICEF: United Nation International Children Fund; VAD: Vitamin A Deficiency; VADD: Vitamin A Deficiency Disorder; WHO: World Health Organization; X1B: Bitot's Spot; $\mathrm{XN}$ : Night Blindness

\section{Acknowledgements}

Authors would like to thanks for Institute of Public Health, College of Medicine and Health sciences, University of Gondar for giving an opportunity to study in this area. In addition, our gratitude goes to Lay Arimachiho district health office staff members for their co-operation by providing necesary information. Finally, we would like thanks the study participants and data collectors.

\section{Author's contributions}

$A B$ was involved in the conception, design, analysis, interpretation, report and manuscript writing. AT and AD were also involved in the design, analysis, interpretation of the data, and manuscript writing. All authors read and approved the final manuscript.

Funding

The principal investigator was the sponsor for this study. 


\section{Availability of data and materials}

Data will be available upon reasonable request from the corresponding author. However, the data cannot be made public to maintain mother's privacy and legal reasons as it contains private health information along with identifiers.

\section{Ethics approval and consent to participate}

Ethical clearance was obtained from the Ethical Review Committee of Institute of Public Health, University of Gondar as per Ref. No /IPH/2397/ 2016. Before communicating the participants' official permission letter of cooperation was obtained from Amhara National Regional State Health Bureau, North Gondar zonal health department, Lay Armachiho district health office and respective kebeles. Written informed consent was taken from each participants. Each eligible study participant was informed about the purpose and importance of the study. Participants got also the assurance that their name were not written on the questionnaire and confidentiality of the data kept at all levels.

\section{Consent for publication}

Not applicable.

\section{Competing interests}

The authors declare that they have no competing interests.

\section{Author details}

${ }^{1}$ Amhara National Regional State Health Bureau, Tikldengay Health Center, Tikldengay, Ethiopia. ${ }^{2}$ Department of Human Nutrition, Institute of Public Health,College of Medicine and Health Sciences, University of Gondar, Gondar, Ethiopia. ${ }^{3}$ Department of Health Systems and Policy, Institute of Public Health,College of Medicine and Health Sciences, University of Gondar, Gondar, Ethiopia.

Received: 25 February 2019 Accepted: 5 December 2019 Published online: 18 December 2019

\section{References}

1. West K Jr. Vitamin A deficiency: health, survival, and vision. New York: Oxford University Press; 1996.

2. Clagett-Dame M, DeLuca HF. The role of vitamin a in mammalian reproduction and embryonic development. Annu Rev Nutr. 2002;22(1):347-81.

3. Dr Jan Sambrook: Vitamin A Deficiency | Patient. https://patient.info , Healthy Living > Health Info. Dec 10, 2018.

4. Kumar S, Chatzi C, Brade T, Cunningham TJ, Zhao X, Duester G. Sex-specific timing of meiotic initiation is regulated by Cyp26b1 independent of retinoic acid signalling. Nat Commun. 2011;2:151.

5. InternationalVitaminConsultativeGroup. Maternal night blindness: a new indicator of vitamin A deficiency. In: IVACG statement. Washington: International Vitamin A Consultative Group; 2002.

6. WHO. Global Database on Vitamin A Deficiency. Geneva: DHS Statcompiler; 2007.

7. WHO. Global prevalence of vitamin A deficiency in populations at risk 1995-2005: WHO global database on vitamin A deficiency. Geneva: World Health Organization; 2009.

8. Gebreselassie SG, Gase FE, Deressa MU. Prevalence and correlates of prenatal vitamin A deficiency in rural Sidama, Southern Ethiopia. J Health Popul Nutr. 2013;31(2):185.

9. Seid O, Tsadik M, Kassa N. Night blindness is a serious public health problem of pregnant women's in Tahtay Koraro District, Tigray region, northern Ethiopia. Journal of Food and Nutrition Sciences. 2015;3(1):17-23.

10. Samba C, Tchibindat F, Gourmel B, Houzé P, Malvy D. Prevalence of vitamin A deficiency in pregnant and lactating women in the Republic of Congo. J Health Popul Nutr. 2013;31(1):28.

11. L: K. Prevalence and associted factors of night blindness among pregnant and lactating mothers in Neadir woreda, Tigray region (unpublished article); 2010.

12. Demissie T, Ali A, Mekonen Y, Haider J, Umeta M. Magnitude and distribution of vitamin a deficiency in Ethiopia. Food Nutr Bull. 2010;31(2):234-41.

13. Semba R, De Pee S, Panagides D, Poly O, Bloem M. Risk factors for nightblindness among women of childbearing age in Cambodia. Eur J Clin Nutr. 2003:57(12):1627.

14. Katz J, Tielsch JM, Thulasiraj RD, Coles C, Sheeladevi S, Yanik EL, Rahmathullah L. Risk factors for maternal night blindness in rural South India. Ophthalmic Epidemiol. 2009;16(3):193-7.
15. Kassaye T, Receveur O, Johns T, Becklake MR. Prevalence of vitamin a deficiency in children aged 6-9 years in Wukro, northern Ethiopia. Bull World Health Organ. 2001;79:415-22.

16. Abrha T, Girma Y, Haile K, Hailu M, Hailemariam M. Prevalence and associated factors of clinical manifestations of vitamin a deficiency among preschool children in asgede-tsimbla rural district, North Ethiopia, a community based cross sectional study. Arch Public Health. 2016;74(1):4.

17. Tariku A, Fekadu A, Ferede AT, Abebe SM, Adane AA. Vitamin-a deficiency and its determinants among preschool children: a community based crosssectional study in Ethiopia. BMC Res Notes. 2016;9(1):323.

18. Wolde-Gebriel Z. Micronutrient deficiencies in Ethiopia and their interrelationships: Wolde-Gebriel; 1992.

19. Stoltzfus RJ, Hakimi M, Miller KW, Rasmussen KM, Dawiesah S, Habicht J-P, Dibley MJ. High dose vitamin a supplementation of breast-feeding Indonesian mothers: effects on the vitamin a status of mother and infant. J Nutr. 1993;123(4):666-75.

20. Filteau SM, Rice AL, Ball JJ, Chakraborty J, Stoltzfus R, de Francisco A, Willumsen JF. Breast milk immune factors in Bangladeshi women supplemented postpartum with retinol or ß-carotene. Am J Clin Nutr. 1999;69(5):953-8.

21. Roy S, Islam A, Molla A, Akramuzzaman S, Jahan F, Fuchs G. Impact of a single megadose of vitamin a at delivery on breastmilk of mothers and morbidity of their infants. Eur J Clin Nutr. 1997:51(5):302.

22. World Health Organization. Indicators for assessing vitamin A deficiency and their application in monitoring and evaluating intervention programmes. https://www.who.int/nutrition/publications/micronutrients/vitamin_a_ deficiency/WHO_NUT_96.10/en/.

23. Aemro M, Mesele M, Birhanu Z, Atenafu A. Dietary diversity and meal frequency practices among infant and young children aged 6-23 months in Ethiopia: a secondary analysis of Ethiopian demographic and health survey 2011. J nutr metab. 2013;2013.

24. FAO.: Baseline Survey Report Protecting and Improving Household Food Security and Nutrition in HIV/AIDS Affected Areas in Manica and Sofala Province, Maputo_Mozambique.2006. http://www.fao.org/fileadmin/user_ upload/eufao-fsi4dm/doc-training/baseline_june07.pdf.

25. Bhutta Z, Soofi, S., Zaidi, S., Habib, A., Hussain m. (2011). : Pakistan National Nutrition Survey, 2011.Available at: http://ecommons.aku.edu/pakistan_fhs_ mc women childhealth_paediatr/262.

26. Ahmed F, Azim A, Akhtaruzzaman M. Vitamin a deficiency in poor, urban, lactating women in Bangladesh: factors influencing vitamin a status. Public Health Nutr. 2003;6(5):447-52.

27. Dreyfuss ML, Stoltzfus RJ, Shrestha JB, Pradhan EK, LeClerq SC, Khatry SK, Shrestha SR, Katz J, Albonico M, West KP. Hookworms, malaria and vitamin a deficiency contribute to anemia and iron deficiency among pregnant women in the plains of Nepal. J Nutr. 2000;130(10):2527-36.

28. West KP Jr. Vitamin A deficiency disorders in children and women. Food Nutr Bull. 2003:24(4 suppl2):S78-90.

29. DHS Statcompiler: Global Database on Vitamin A Deficiency, [Internet]. [cited 12/2/2012].2007. Available from: http://www.statcompiler.com/index.cfm.

30. Christian P, West KP Jr, Khatry SK, Kimbrough-Pradhan E, LeClerq SC, Katz J, Shrestha SR, Dali SM, Sommer A. Night blindness during pregnancy and subsequent mortality among women in Nepal: effects of vitamin a and $\beta$ carotene supplementation. Am J Epidemiol. 2000;152(6):542-7.

31. Chakona G, Shackleton C. Minimum dietary diversity scores for women indicate micronutrient adequacy and food insecurity status in south African towns. Nutrients. 2017;9(8):812.

\section{Publisher's Note}

Springer Nature remains neutral with regard to jurisdictional claims in published maps and institutional affiliations. 